\title{
Cross-Cultural Communication in Pre-University Training of Foreign Students
}

\author{
Natalia Filimonova \\ Volgograd State Technical \\ University \\ Faculty of Preparation of Foreign \\ Specialists, \\ Chair of Russian language \\ Volgograd, Russia \\ filimonova_n@rambler.ru \\ Elena Romanyuk \\ Volgograd State Technical \\ University \\ Faculty of Preparation of Foreign \\ Specialists, \\ Chair of Russian language \\ Volgograd, Russia \\ romanuk-elena9@mail.ru
}

\author{
Aleksey Godenko \\ Volgograd State Technical \\ University \\ Faculty of Preparation of \\ Foreign Specialists \\ Volgograd, Russia \\ forstud@ vstu.ru
}

\author{
Olga Ergunova \\ The Ural State University of \\ Economics, Department of \\ regional and municipal economics \\ and management \\ Ural Federal University named \\ after the first President of Russia \\ B.N.Yeltsin, Department of \\ Integrated Marketing \\ Communications and Branding \\ Yekaterinburg, Russia \\ forstud@vstu.ru
}

\begin{abstract}
The article analyzes the implementation of intercultural communication of foreign students in the conditions of international faculties within Russian universities. The authors consider intercultural communication of foreigners as their ability to communicate in the studied language with the adoption of the basic values of that new social and cultural environment. Attention is drawn to the role of the teacher in the organization of intercultural pedagogical communication. The necessary qualities that a teacher working with foreign students should possess are characterized. The stages in the formation of intercultural communication, leading to the adaptation of students to a new social and academic environment, are also considered. This thesis expresses the necessity of studying the national-psychological characteristics belonging to the representatives of different regions of the world. The paper presents the results of the author's study on the classification of main national-psychological characteristics of foreign students from different countries, whose representatives study at the Volgograd State Technical University. The authors also provide the recommendations on organizing intercultural communication with different foreign contingents.
\end{abstract}

Keywords - intercultural communication, international faculty, clash of cultures.

\section{INTRODUCTION}

A modern Russian university is a multicultural space where foreign students from many countries interact. It is here that a dialogue of cultures of representatives of different peoples occurs. And here intercultural communication of students with each other and with Russian teachers is realized. To introduce foreigners to the Russian socio-cultural and educational space, teachers working with the foreign audience in the university setting should possess the technology, pedagogical models, and mechanisms of intercultural communication, which constitute the basis of professional and pedagogical activity. It can be argued that at the beginning of Russian language acquisition/learning for foreign students, namely at the pre-university stage of education, there occurs a clash of cultures. This is described as when foreigners experience a difficult period in adaptation and acculturation, and teachers should attempt to minimize the consequences of early intercultural contact as much as possible. Pedagogical communication in a foreign university audience is dependent on the level of pedagogical and psychological training of teachers. Presently, one can talk about the unpreparedness of pedagogical university graduates to pedagogical activity in the classroom with foreign students. Therefore, the goal of our work is to investigate the national and psychological qualities of foreign students within international faculties of the Russian universities and to offer teachers working with the foreign audience to apply the given recommendations on organizing intercultural pedagogical communication with representatives from different regions.

\section{II.RESULTS AND DISCUSSION}

\section{A. The Theory of Intercultural Communication.}

In Russia, the pre-university stage is an obligatory part of education for foreign students, there are also similar practices in other countries [1]. At the same time, pedagogical communication is regarded by us as a specific form of interaction between subjects of intercultural communication. In this study, we draw attention to the fact that work in a foreign university audience assumes the basic thesis on the close relationship of pedagogical and intercultural communication [2]. The founder of this theory of intercultural communication is Edward Hall, a representative from the American School of Cultural and Linguistic Anthropology. The main conclusion of this theory specified the need to learn not only a foreign language but also the culture [3]. Among the founders of this theory of intercultural communication, we find such foreign scientists as D. Treiger, V. Goodikunst, M. Bennett, G. Hofstede and others. In the Russian science, the work of researchers prevails in the field of Russian as a foreign lathe nguage: E. M. Vereshchagin, I. A. Zimnya, V. G. Kostomarov, A. N. Leontiev, O. D. Mitrofanova, E. I. Passov, and many others.

Now, intercultural communication is the subject of consideration for many different sciences, from philosophy to pedagogy. Pedagogical works in the field of intercultural communication were written by $\mathrm{V}$. V. Davydov, I. D. Zverev, V. N. Maksimova, Yu. A. Samarin, L. I. Kharchenkova, A. N. Shchukin and others. Intercultural communication has become a separate 
academic subject. A general and specific theory is also found in aspects of studies within other subjects. Intercultural communication of foreign students is categorized as their ability to communicate in the studied language with the adoption of the basic values of the new social and cultural environment. A teacher who works with foreign students requires respect for the student's personality, pedagogical tact, understanding and tolerance to other attitudes, a high level of professionalism, and general erudition.

\section{B. The role of the teacher in intercultural pedagogical communication}

The role of the teacher in intercultural pedagogical communication assumes that the student is an equal participant in the dialogue. The teacher needs to develop motivation and readiness for intercultural communication among the foreign students. Ability to communicate is the main competence of students when learning to speak, and development of this quality presupposes the presence of certain verbal and non-verbal means, features of speech and behaviour. It is necessary to note the very important role played by non-verbal means in cross-cultural communication. Researchers argue that with the help of verbal means a person transmits only $20 \%$ of the information. Therefore, the teacher should be very attentive to a foreign audience, pay attention to their gestures, phonetic parameters of speech and much more.

The teacher should teach students to understand the characteristics of their culture and distinguish it from the culture studied in order to compare the qualities of different cultures as well as to adopt common values. Tolerance can be understood not only as tolerance to a foreign culture, but also as its ultimate degree - empathy, or the ability to perceive another culture as one's own. For this, the teacher must use various forms of work, from individual to collective. Within the classroom setting and during the extra-curricular time there should be a pleasant atmosphere. In connection with the important role of the teacher in intercultural communication it is necessary to consider the concept of 'communication style'. The concept of an individual style is determined by the personality traits of the teacher and his character. In the process of teaching Russian as a foreign language, each teacher uses his own, individual style of communication, his own ways and means of communication. This is especially important at the initial stage of training, because teaching a foreign language from scratch and subjects in a foreign language occurs in close contact with students, in a small audience, every day for several hours. There is a certain pattern: the closer is the interaction between the teacher and the students, the more important is the teacher's communication style. Researchers recognize that the most optimal is the style of communication, based on enthusiasm for the joint creative activity. Passion for the common cause is an important source of educational and scientific activity for foreign students in a Russian university. This style of communication can be most effective in writing and preparing for the presentation of coursework at the preparatory faculty and in the future, when writing other research papers, including diploma and thesis. It is used in preparation for speeches at congresses of the Association of Foreign Students, general and national evenings, concerts, olympiads and various excursions, in class and during the extra-curricular time. This style is a prerequisite for the successful formation of the intercultural communication foundations. At the preuniversity stage of education, the professional and creative growth of students largely depends on the work of the Russian language teacher, because he can either stimulate and develop their creative and scientific initiative or inhibit it. In our opinion, the style of communication with foreign students can be different in different cases. For example, African or Chinese students normally perceive the authoritarian style of the teacher's communication in the classroom, and in the Vietnamese or the Arab group, democratic style is quite appropriate. Chinese educational traditions are an authoritarian teacher, and Chinese students are getting used to the friendly, democratic style of communication between Russian teachers. African students are accustomed to a 'harder' style of communication with the teacher at home, and they can perceive our style of communication in the audience as flirting. The combination of several styles in different situations in teaching can be considered an integrative style of communication. The style of pedagogical intercultural communication should be natural, democratic, informal. He cannot be dictatorial and humiliating for students.

The teacher plays an important role in the organization of professional and pedagogical communication with foreign students and the formation of the intercultural communication foundations. We highlight the necessary qualities that a teacher who works with foreign students should possess:

- high professionalism;
- erudition;
- pedagogical tact;
- tolerance to the views of others;
- active position;
- respect for the student's personality;
- benevolence.

Of course, all of the above is necessary for every university teacher, but some additional qualities are required of a teacher who organizes communication with foreigners due to the specifics of this pedagogical activity at the junction of two or several cultures [4]. A teacher for foreign students is, above all, a representative of the Russian reality and the Russian culture. The teacher is the main source of information for foreign students in this new socio-cultural environment. At the initial stage of acquisition, this is usually the first person with whom the foreigner communicates closely and daily, therefore should meet specific requirements. The role of the teacher in pedagogical intercultural communication is that he must: 
- consider a student as the main participant in pedagogical communication and pay attention to his personality;

- develop the foreign student's motivation for intercultural communication;

- encourage the foreign student to learn the characteristics of his culture in comparison with other cultures;

- develop communicative abilities as the ability of foreign students to communicate (speech, behavior, nonverbal means);

- cultivate tolerance as a willingness of foreign students to effective intercultural communication;

- if possible, form empathy by means of pedagogical communication as the ability to sympathize, empathize with another person, especially, belonging to a group of a different culture;

- use individual, group and collective work forms in teaching and extracurricular activities of the teacher;

- create a comfortable and welcoming atmosphere both during classes and out-of-class activities;

- develop the speech, creativity, research abilities of students;

- and finally to prevent and eliminate interpersonal and intercultural conflicts of foreign students.

Hence, we listed the qualities that a teacher, who organizes communication with foreigners, should have, and have determined his role in pedagogical intercultural communication. But within the framework of this article, it is necessary to emphasize the specificity of a foreign audience with its' diversity of cultures, traditions, customs, national mentality, and national psychological characteristics of students all combined collectively.

\section{Variety and Classification of Cultures.}

At the pre-university stage of education in Russian universities, the clash of cultures is due to their differences; such as the dependence of foreign students on stereotypes, rejection of other people's rules, communication skills, and intercultural differences. Misunderstanding between representatives of peoples and cultures will be all the more important, the further apart these cultures are in origin. Note that in this paper, the authors consider a culture as a set of differences in the activities of representatives of different nations, nationalities, and ethnic groups, which determines the uniqueness of the picture of the world, lifestyle, mentality and national character. In discords between communicants belonging to different cultures, interpersonal conflicts often arise due to mismatches in communication skills and contradictions in national behaviour patterns of students who come from different regions. American anthropologist Milton Bennet, with an ethnocentric attitude to other cultures, distinguishes three stages: denial of differences and protection; when a person recognizes differences but perceives them as a threat; and minimization, when he recognizes differences but is confident in basic values. He advocates a sympathetic and empathic approach to communication between representatives of different cultures. According to Bennett, an empathic approach is preferable, this is described as when a person not only puts himself in the place of another but looks at the world through the eyes of another person. A widely used model of intercultural training $M$. Bennett is applicable to the new communication technology, which considers the learning process as several stages replacing each other (from ethnocentrism to the conscious adoption of another's culture). All these stages replace one another at different levels of teaching foreign students, and their replacement depends on many objective and subjective factors. At the same time, the success of training can be conditioned by the application of certain pedagogical methods [5]. While learning, the correct formation of foundations in interpersonal communication between different cultures facilitates the early adaptations of foreign students, as well as the effectiveness of their educational and extracurricular activities. Students have to move from recognizing the differences of the two cultures to adaptation (improving the skills of intercultural communication), then to empathy (the ability to empathize and accept someone else's culture), and finally integration, that is, immersion in a different cultural environment. At each of these stages in the formation of intercultural communication, it is necessary to develop the personality traits of a foreign student, such as communicative ability (tolerance to communication), tolerance [6] (tolerance to an alien culture and readiness for communication) and empathy. At the same time, it is important for the teacher working with foreigners to take into account their value orientations, national psychological characteristics and the specifics of the national mentality. In the present work, we rely on the well-known classification of cultures by the world's leading specialist, Richard Lewis, who defined the general division of cultures and their key features. The main postulates in the art of communication are interaction and mutual understanding. The difference between cultures is the difference between patterns of behaviour. Hence, a possible misunderstanding may arise in certain areas with intercultural contacts. Lewis introduced the concepts of "programming mentality," the style of communication, the transmission, and storage of culture as a collective activity. Edward Hall, as we noted above, subdivided all world cultures into monochrome and polychrome, Richard Lewis classed cultures according to the way they organized their activity in mono-active cultures (Germany, USA, Great Britain, France, Sweden), polyactive cultures (Spain, Italy, Latin America, Arab countries) and reactive cultures (China, Vietnam, Korea, Japan) [7].

According to Lewis, in the world, about 4 billion of all peoples represent a multi-active culture, 2 billion are representatives of a reactive culture. Only 700 million people in the world are linearly active (or monoactive). There are countries with a mixed type of culture, for example, India, Indonesia, Russia, Canada, Belgium, and Israel. Each culture is a certain model of human 
behaviour. The storage and transfer of a culture cannot be individual, it is a collective activity. It can not be programmed, but one is able to plan a communication style. When foreign students come to Russia for an extended period of time, they gradually change and absorb the features of a new culture for themselves. Within each individual culture, it is possible to distinguish regional cultures, since residents of different cities and localities differ from each other. For example, people in St. Petersburg, Moscow, and Volgograd differ from each other for a number of characteristics. Within each type of culture, there are also gender, professional, and religious differences; elements of corporate and personal culture. We agree with the researcher's assessment on the differences between representatives of the three main types of cultures. Representatives of mono-active cultures are focused on the task, punctual and compulsory, they are restrained, polite, most often objective in disputes. Emotional, impulsive, verbose, and not always punctual are qualities often found in representatives of polyactive cultures who often change their plans, but in difficult situations, they are capable of improvisation. Finally, representatives of reactive cultures are often silent, respectful of the interlocutor, and punctual. Representatives of polyactive and reactive cultures often study at the international faculty of Russian universities. Understanding and analyzing the peculiarities of these cultures are possible only when they are compared; which, on the one hand, will help the teacher in interpersonal communication with foreigners to take into account the peculiarities of communication of representatives of different peoples, however on the other - to teach them tolerance towards each other, and besides to teach students the communicative behavior of the native speakers of the studied language. It seems to us necessary to give foreign students an opportunity to acquaint the representatives of other cultures with their ethnos, their traditions and customs, with their native country, that is, to demonstrate themselves as a person belonging to a particular cultural community. With proper work in terms of the formation of intercultural understanding, it becomes possible to talk about the interaction of cultures while preserving their uniqueness [8].

Lewis writes about stereotypes that they often interfere with communication [9]. It should be noted that cultural stereotypes often do not adequately perceive foreign students. Let's give some examples. Vietnamese students, as a rule, are zealous and obligatory students, they are very successful in their studies. But sometimes we meet with the complete opposite, with very weak and lazy students. The idea of Afghan students as weak and poorly trained in technical subjects and without the knowledge of an intermediary language is now incorrect, they come to Russia with a perfect knowledge of English and a good knowledge base in mathematics and other subjects. A Latin American student may not be frivolous and talkative, but a serious philosopher, a thorough and profound person. Thus, stereotypes can both help and hinder teachers in their work. An important factor in intercultural communication is the attitude of representatives of different cultures to the time. Many foreign students, coming to study in Russia, can not clearly plan their school hours. To a greater extent, this applies to representatives of polychrome cultures, Arab and Latin American students. In the first months of school they are often late for classes because such behaviour is considered normal in their countries. They, as representatives of polyactive cultures, cannot concentrate on one activity, doing several things at once. In addition, they have difficulties in performing tests, because they find it difficult to meet at a certain time. In their cultures, time limits do not matter much, the very activity of a person is important. All these moments can cause mutual misunderstanding between students and teachers. It seems that at a certain stage the teacher needs to be more loyal in relation to such behavioural features. Another important factor in intercultural communication is the category of space. It is very different in the cultures under consideration. In this case, we can talk about the distance between the teacher and students - representatives of different cultures.

\section{Accounting for the national-psychological characteristics of foreign students.}

Specificity of the teacher's communication with representatives of different cultures depends on the national-psychological characteristics of foreign students, their value orientations and the specificity of their national mentality. Given that currently in Russia university and postgraduate education receives more than 200 thousand foreign citizens from 170 countries and to describe all cultures is not possible, the authors of this article tried to determine the essential features for organizing pedagogical communication of foreign students from the countries, most frequently met at Russian universities. The study was conducted in several stages. First, the lists of foreigners who studied at the preparatory faculty of the Volgograd State Technical University were analyzed for forty years. Then the students were divided into five large groups by region and other criteria. Thus, Englishspeaking (Zambia, Nigeria, Kenya, Zimbabwe, Tanzania, etc.) and French-speaking (Congo, Mali, Senegal, Togo, etc.) African students differed in the language, culture and the national educational system became the different groups. The following three groups included foreign students from the Middle East and North Africa (Algeria, Jordan, Iraq, Yemen, Lebanon, Morocco, Palestine, etc.), from Asia (Afghanistan, Bangladesh, Vietnam, India, China, Korea and etc.) and from Latin America (Bolivia, Venezuela, Colombia, Peru, Chile, Ecuador). Thus, in these groups, there were the representatives of polyactive and reactive cultures. At the next stage of the work, we summarized the main national-psychological characteristics of foreign students from different regions and presented them in Table I below. In connection with the fact that the theoretical observations and results of these observations are presented in our monograph "Intercultural Communication in the Conditions of the International Faculty" [2], we give only one fragment that generalizes the national psychological characteristics of students from Southeast Asia (see Table I). 
TABLE I

NATIONAL-PSYCHOLOGICAL CHARACTERISTICS OF STUDENTS FROM SOUTHEAST ASIA

\begin{tabular}{|c|c|c|c|c|}
\hline Region & Qualities of personality & Educational activity & Emotional sphere & Behaviour in a group \\
\hline $\begin{array}{l}\text { Countries of } \\
\text { South-East } \\
\text { Asia }\end{array}$ & $\begin{array}{l}\text { Shyness, conscience, } \\
\text { consciousness; } \\
\text { ambition, stubbornness, } \\
\text { non-compactness; a } \\
\text { sense of duty and self- } \\
\text { esteem. }\end{array}$ & $\begin{array}{l}\text { Easy and quick assimilation of new } \\
\text { information, highly developed } \\
\text { abstract thinking, conscientiousness, } \\
\text { efficiency, pedantry, thoroughness, } \\
\text { self-confidence and someone's } \\
\text { knowledge. }\end{array}$ & $\begin{array}{l}\text { External restraint, } \\
\text { control over } \\
\text { emotions and } \\
\text { behaviour, concern } \\
\text { for reputation. }\end{array}$ & $\begin{array}{l}\text { For the most part, group activities prefer } \\
\text { to work alone, the student collective } \\
\text { neglects unity, does not need the approval } \\
\text { and support of the group, are cautious in } \\
\text { their actions, always under self-control. } \\
\text { The conflict is extremely rare. }\end{array}$ \\
\hline
\end{tabular}

The final stage of the study of the nationalpsychological qualities of foreign students became recommendations on the organization of intercultural pedagogical communication with representatives of different regions, offered to teachers working with a foreign audience. We will demonstrate some of the recommendations concerning the work with students from the countries of Southeast Asia. Among the total number of foreign students coming to study from different countries of the world, citizens from the countries of Southeast Asia are $29.7 \%$ [10, p.22], therefore the study of their national psychological characteristics is dictated by the practical need to communicate productively with so many Asian students. We will give the following recommendations for the teachers working with this contingent:

a) the behaviour of the representatives of the countries of Southeast Asia differs from the European one, which is explained by the significant difference between Eastern culture and Western culture;

b) when forming high-performance training groups at the initial stage of training, it makes sense to unite students from the countries of Southeast Asia into one group;

c) it is important to remember that working with students from Southeast Asia requires teachers to be seriously prepared, as these students show interest in art and creativity, the meaning of life and intellectual issues;

d) do not overly 'patronize' these students, as in the majority they are quite independent people who have a developed system of values and a habit of meeting the demands placed on them.

It is known that students from Southeast Asia - this is an interesting, but quite difficult contingent with a peculiar style and motives of behaviour. At the same time, being residents of countries with a reactive culture of behaviour, they are the easiest to adapt to other nations. It should be acknowledged that in addition to the unifying qualities, one can name a sufficient number of features that distinguish the peoples of the countries of the Southeast ern region. But we agree with the authors of the monograph "Socio-psychological and physiological problems of adaptation of foreign students," that "there are no specific features that are unique to one nation. Specific differences of one ethnic community from another are in the degree of intensity of these features" [11, p. 49].

\section{CONCLUSION}

Recommendations for the integration of national and psychological characteristics of representatives of different regions of the world, proposed by our teachers working in a Russian university with foreign students, help in the modelling of pedagogical situations. We affirm that teachers need to reckon with the national mentality of foreigners. "To take into account the national mentality of foreigners is necessary for the organization of classroom and extracurricular activities so that differences in national cultures, national psychological characteristics of foreign students do not lead to problems of intercultural communication" [2, p.192]. In the monograph we compare Chinese and African educational traditions, paying attention to the fact that students from these regions are accustomed to an authoritarian teacher and his rather 'hard' style of communication. Therefore, Chinese students are surprised by the friendly, democratic style of communication of Russian teachers, and Africans can perceive the informal, friendly manner of communication as flirtation. Thus, even the individual style of the teacher's communication should vary depending on the particular contingent. And this means that for successful intercultural communication the teacher needs an idea of the ethnic characteristics of students. Failure of the teacher to understand the national features of the contingent can lead to violations of normal communication. That is why we "distinguished the differences in the qualities of the individual, the emotional sphere, the peculiarities of the learning activity and the behavior of the students in the group, after which recommendations for the organization of pedagogical intercultural communication were given to the teaching practitioners working with foreign applicants at the stage of pre-university training" [8]. Knowledge of the nationalpsychological characteristics of foreign students who study in the multicultural space of the international faculty of the Russian university will allow the teacher to build pedagogical intercultural communication on the basis of a dialogue with representatives of different regions. This will help foreigners to successfully adapt to the new socio-cultural environment and the new pedagogical system.

\section{REFERENCES}

[1] Ai. Xin, "The Enlightenment of Internationalization of Higher Education on Foreign Language Education," in Advances in Social Science, Education and Humanities Research, Proceedings of the 3rd International Conference on Social Science and Higher Education, 2017. 
[2] N.J. Filimonova, and E.S. Romanyuk, "Intercultural communication in the conditions of international faculty," Monograph, Volgograd State Technical University, Volgograd, 2015, 224 p. (in Russian).

[3] E. Hall, "The Silent Language," M., 1995, 432 p.

[4] W. Jin, "English Language Teaching in Cross-Cultural Contexts," CELEA, 2004, Vol. 27, No. 1, pp.55-58.

[5] Milton J. Bennett, "Basic Concepts of Intercultural Communication," Selected Readings, Yarmouth, 288 p., 1998.

[6] Deni Adi Wijaya, Djono and dan Suryo Ediyono, "The Attitude of socio-harmony and Local Wisdom: an Indicator of the Development of Social Tolerance of High School Students", in SHS Web of Conferences, Volume 42 (2018). Global Conference on Teaching, Assessment, and Learning in Education (GC-TALE 2017). Sanur, Bali, August 28-29, 2017, Published online: 29 January 2018, DOI: https://doi.org/10.1051/shsconf/20184200049, (date of access: 10.05.2018).
[7] R.D. Lewis, "When cultures collide: managing successfully across cultures," Rev. ed. International Press Inc., Nicholas Brealey Publishing, London, 2003, pp. 36-45.

[8] N. Filimonova, A. Godenko, and E. Romanyuk, "Pre-university training of foreign students as the beginning of the formation of cross-cultural communication," in British Journal of Science, Education and Culture, vol. III, No. 1 (7), pp.499-505, 2015.

[9] R. Lewis, "Cross-cultural communications in the modern world: problems of theory and practice," Selected lectures of the University, Issue 154, St.Petersburg, SPbSUP, 164 p., 2013.

[10] A.L. Arefiev, "Training of foreign citizens in higher educational institutions of the Russian Federation: Statistical compilation," Issue 10, Ministry of Education and Science of the Russian Federation, Moscow, Center for Sociological Research, 2013, 139 p. (In Russian).

[11] D.G. Arseniev, A.V. Zinkovsky, and M.A. Ivanova, "Sociopsychological and physiological problems of adaptation of foreign students," St. Petersburg, Publishing house of SPbSPU, 2003, 160 p. (In Russian) 